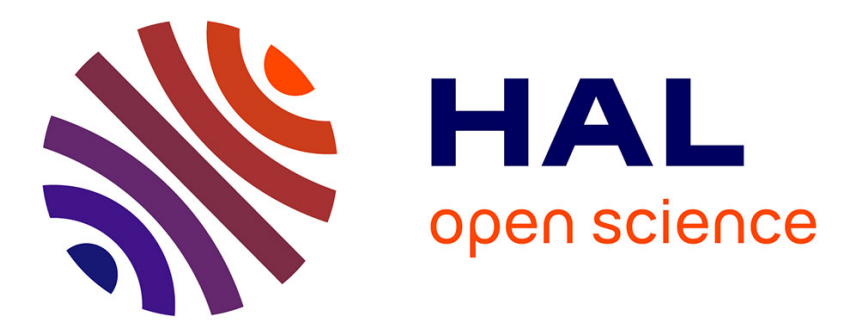

\title{
High Glass-Transition Temperature Polymer Networks Harnessing the Dynamic Ring Opening of Pinacol Boronates
}

\author{
Juliette Brunet, Franck Collas, Matthieu Humbert, Lionel Perrin, Fabrice
} Brunel, Emmanuel Lacote, Damien Montarnal, Jean Raynaud

\section{To cite this version:}

Juliette Brunet, Franck Collas, Matthieu Humbert, Lionel Perrin, Fabrice Brunel, et al.. High Glass-Transition Temperature Polymer Networks Harnessing the Dynamic Ring Opening of Pinacol Boronates. Angewandte Chemie International Edition, 2019, 58 (35), pp.12216-12222. 10.1002/anie.201904559 . hal-03006422

\section{HAL Id: hal-03006422 \\ https://hal.science/hal-03006422}

Submitted on 16 Nov 2020

HAL is a multi-disciplinary open access archive for the deposit and dissemination of scientific research documents, whether they are published or not. The documents may come from teaching and research institutions in France or abroad, or from public or private research centers.
L'archive ouverte pluridisciplinaire $\mathbf{H A L}$, est destinée au dépôt et à la diffusion de documents scientifiques de niveau recherche, publiés ou non, émanant des établissements d'enseignement et de recherche français ou étrangers, des laboratoires publics ou privés. 


\title{
High glass-transition temperature polymer networks harnessing the dynamic ring opening of pinacol boronates
}

\author{
Juliette Brunet ${ }^{[a]}$, Franck Collas ${ }^{[b]}$, Matthieu Humbert ${ }^{[a]}$, Lionel Perrin ${ }^{[c]}$, Fabrice Brunel ${ }^{[a]}$, Emmanuel \\ Lacôte $^{[\mathrm{d}]}$, Damien Montarnal ${ }^{\star[a]}$, Jean Raynaud*[a]
}

Dedication ((optional))

\begin{abstract}
Differential scanning calorimetry of high molar mass poly(4vinylphenylboronic acid, pinacol ester)s evidenced unusual reactive events above $120^{\circ} \mathrm{C}$, resulting in a high glass transition temperature of $220^{\circ} \mathrm{C}$. We hypothesize a ring-opening reactivity of pinacol boronates involving a nucleophilic attack on the $\mathrm{sp}^{2}$ boron and subsequent bridging by interconnected pinacol moieties to form a densely crosslinked network with high-T. FTIR, solid-state NMR investigations and rheology studies on the polymer as well as doubletagging analyses on molecular model structures and theoretical calculations further support this hypothesis and indicate an entropydriven ring opening inducing crosslinking. When diluted in an apolar solvent such as toluene, the polymer network can be resolubilized via ring closing thus recovering the entropically-favoured linear chains featuring cyclic boronate esters. The introduction of boron reactivity in polymer chains may open a path to a new class of dynamic polymer networks with uncommon and exciting thermodynamics.
\end{abstract}

\section{Introduction}

Polymers comprising boronic/boronate groups have been the focus of intensive research due to their unique properties associated with the electron deficiency of boron conferring reactivity harnessed via post-polymerisation. ${ }^{1,2}$ Simple nucleophilic coordination at the boron vacancy enables further versatile functionalisations and precise macromolecular engineering. To perfectly tune the reactivity at boron, synthetic chemists have developed a wide array of substituents, from conventional boronates to MIDA esters. ${ }^{3-7}$ Challenging metalcatalysed $\mathrm{C}-\mathrm{C}$ couplings and orthogonal functionalizations were achieved by appropriately selecting the boron moieties. ${ }^{7}$ For instance, one can hydrolyse boronate esters, or fluoro-derivatise them to yield organotrifluoroborates. In both cases, a nucleophilic attack at the boron vacancy is involved..$^{3,7}$ In the presence of 1,2 or 1,3-diols, boronic acids are in fast equilibrium at room

[a] J. Brunet, M. Humbert, Dr. F. Brunel, Dr. D. Montarnal, Dr. J. Raynaud.

Univ Lyon, Université Claude Bernard Lyon 1, CPE Lyon, CNRS, Laboratory of Chemistry, Catalysis, Polymers and Processes (C2P2, UMR 5265)

43 Bd. Du 11 Novembre 1918, F-69616 Villeurbanne, France E-mail: damien.montarnal@univ-lyon1.fr, jean-raynaud@univlyon1.fr

[b] Dr. F. Collas

Mettler-Toledo SAS

$18 / 20$ avenue de la Pépinière, 78222 Viroflay cedex, France

[c] Dr. L. Perrin

Univ Lyon, Université Claude Bernard Lyon 1, CPE Lyon, INSA

Lyon, ICBMS, CNRS UMR 5246, Equipe ITEMM

43 Bd. du 11 Novembre 1918, 69622 Villeurbanne, France

[d] Dr. E. Lacôte

Univ Lyon, Université Claude Bernard Lyon 1, CNRS, CNES,

ArianeGroup, Laboratoire Hydrazines et Composés Energétiques

Polyazotés (LHCEP, UMR 5278)

Bât. Raulin, 2 rue Victor Grignard, F-69622 Villeurbanne, France

Supporting information for this article is given via a link at the end of the document.((Please delete this text if not appropriate)) temperature with boronate esters and water. This transesterification equilibrium can be shifted with the help of a desiccant or exploited in numerous molecular recognition or chemosensing applications ${ }^{8}$ such as $\mathrm{pH}$-dependent complexation of various carbohydrates ${ }^{9}$ or smart drug delivery systems. ${ }^{10}$ Following similar approaches, covalent dynamic crosslinking of organoboron polymers is receiving a growing interest in the context of materials with high mechanical performances and facilitated recycling or processing..$^{11,12}$

Such crosslinks with externally adjustable dynamics (e.g. using temperature or light) are sought-after as they confer both the benefits of thermosets in conditions of slow dynamics (e.g. creep and stress-cracking resistance) and malleability, plasticity, weldability or recyclability in conditions of fast dynamics. A distinction can be made between dynamic polymer networks featuring a constant crosslink density with accelerated crosslink reshuffling upon heating, i.e. vitrimers, ${ }^{13-15}$ and networks featuring both a decreased crosslink density and shorter crosslink-bond lifetimes upon heating or UV-irradiation ${ }^{16}$, i.e. covalent adaptable networks (CANs). ${ }^{17-20}$

Based on both the transesterification equilibrium and the aforementioned reactivity at boron, CANs gels in toluene have been obtained by adding bis(boronate ester) crosslinkers in polycyclooctene-containing vicinal diol moieties. The exchanges can be tuned by strategically positioning secondary amines in the vicinity of the boron atoms, which greatly accelerates exchange dynamics. ${ }^{21}$ Recently, Nicolaÿ, Leibler and coworkers disclosed fascinating covalent exchangeable vitrimers crosslinked by dynamic exchange of boronate ester linkages, albeit the actual exchange mechanism still remains unsolved. ${ }^{22}$

To the best of our knowledge, none of the dynamically crosslinked materials described so far reach the very high glass transition temperatures $\left(\mathrm{T}_{\mathrm{g}}\right.$ above $\left.200^{\circ} \mathrm{C}\right)$ required for adhesives, protective coatings, low-wear or low-friction materials when exposed to high temperatures (contact with hot parts, composites for aerospace, electronics, bearings...). For such demanding applications, only a few thermoplastics constituted of very rigid segments, with various degrees of solubility and processability are commercially available (e.g. polyaryletherketones, polyethersulfones, polyaramides, polyetherimides or polybenzimidazoles). ${ }^{23}$ Alternatively and historically, one can use non-reprocessable, very densely crosslinked thermosetting resins such as maleimide or phenolic formaldehyde, or specialty epoxies. ${ }^{24}$

All vitrimers disclosed so far have moderate crosslink densities, and exhibit therefore two clearly distinguishable relaxations: the conventional glass-to-rubber transition involving cooperative mobility at the polymer-segment scale and a second rubber-toliquid transition dictated by crosslink exchanges and dynamic rearrangements of the network topology at the network-mesh scale, and thus with a viscous flow activation energy (e.g. the temperature-dependence of the viscosity) matching the activation energy of the exchange reaction. Although the rubber-to-liquid transition can occur at very high temperatures in systems with 
sluggish exchange kinetics, the glass-to-rubber transition is contingent on the rigidity of the backbone in-between crosslinks and was not reported so far beyond $166^{\circ} \mathrm{C} .{ }^{25}$ Some CANs feature very rigid and densely crosslinked backbones, but their $\mathrm{Tg}$ is limited by de-crosslinking of the network at elevated temperatures: rigid furane-maleimide networks undergo a unique glass-to-liquid transition around $120^{\circ} \mathrm{C} .{ }^{17}$ The viscous flow activation energies are typically much higher in CANs than in vitrimers, as they result both from the dynamics of reversible bonds and the de-crosslinking of the network.

In this article we report that poly(4-vinylphenyl-pinacol-boronate ester) (PSBPin, Figure 1) exhibits a very high $\mathrm{T}_{\mathrm{g}}$ up to $220^{\circ} \mathrm{C}$. Although the bulky pinacol ester group is expected to reduce the chain mobility in comparison to polystyrene, the rigidity in the polymer structure and the polar interactions cannot account for such a high $\mathrm{T}_{\mathrm{g}}$. This compelled us to further explore the dynamics of this polymer linked to the reactivity of the pendant cyclic boronate. Herein we unveil a reaction mechanism involving dynamic and reversible ring openings of the cyclic boronate moieties at high temperatures.

\section{Results and Discussion}

The phenylboronate polymer was prepared via free radical polymerization of 4-vinylphenyl-pinacol-boronate ester. ${ }^{1,26,27}$ The organoboron monomer was prepared via esterification with pinacol of the corresponding phenylboronic acid. It is important to note that the monomer always contains minute amounts of pinacol $\left(<1 \mathrm{~mol} \%\right.$ by $\left.{ }^{1} \mathrm{H} \quad \mathrm{NMR}\right)$, and we carried out polymerizations without further purification. This contamination will be discussed later on as a putative source of nucleophiles for initiating the ring opening mechanism. Careful optimization of polymerization temperatures, (non-transferable) solvents and initiator concentrations allowed us to obtain PSBPin with Mw as high as $200 \mathrm{~kg} \cdot \mathrm{mol}^{-1}$ (see Supporting Information, SEC discussion and Fig. S14 to S17). This high-mass material was used for the rest of the study, though comparisons are drawn with lower molarmass PSBPin in SI (Fig S7 \& S8).

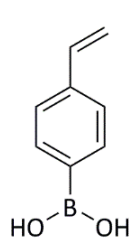

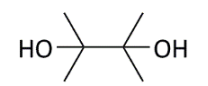

Drying agent $\left(\mathrm{MgSO}_{4}\right)$

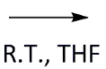

R.T., THF<smiles>C=Cc1ccc(CCCC)cc1</smiles>
peroxide, $70^{\circ} \mathrm{C}$, toluene<smiles>CB1OC(C)(C)C(C)(C)O1</smiles>

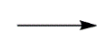

$\longrightarrow$ observed when lower molar-mass PSBPin were utilized (see comparison between Fig. S7 \& S8). Additionally, it is possible to finely tune the $\mathrm{T}_{\mathrm{g}}$ of the final material by simple copolymerization with styrene using similar methodology (see Fig. S10 \& S11 for DSC). Thermogravimetric analysis (TGA) of the fresh sample did not reveal any significant weight loss in the $25-200^{\circ} \mathrm{C}$ range (Figure $\mathrm{S} 13$ in $\mathrm{SI}$ ), which ruled out a mere evaporation of plasticizers. We therefore surmised that the polymer had been chemically transformed, resulting in a very high $\mathrm{T}_{\mathrm{g}}$ polymer after the initial heating step. Additional experiments ran in highpressure sealed pans enabled to suppress most evaporation endotherms (Figures S7 \& S9, SI). In such conditions, we observed a unique endotherm between 90 and $110^{\circ} \mathrm{C}$. In this case the $\mathrm{T}_{\mathrm{g}}$ is lowered to $160^{\circ} \mathrm{C}$, even after multiple heating cycles.

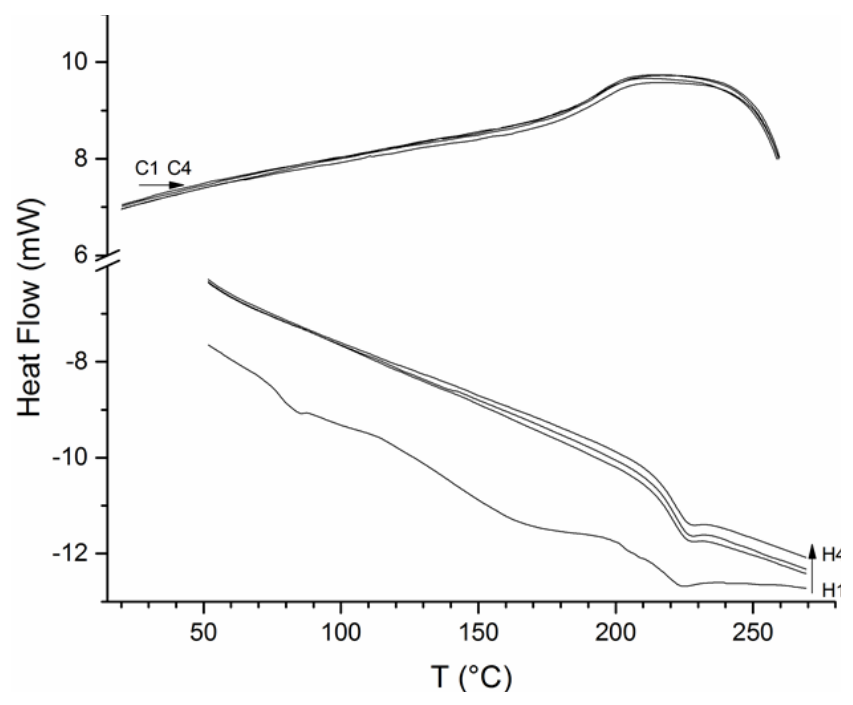

Figure 2. DSC thermograms (Exo up) of PSBPin at $20 \mathrm{~K} / \mathrm{min}$. $\mathrm{H} 1-4$ and $\mathrm{C} 1-4$ are the successive heating and cooling ramps, respectively. Traces are cut at the beginning of each cooling and heating ramp for clarity.

In order to better characterize the polymer after the heating step, we investigated its viscoelastic properties from 230 to $260^{\circ} \mathrm{C}$ by shear rheology, using small amplitude oscillations. Frequencydependent storage and loss moduli at different temperatures were shifted by conventional time-temperature superposition in order to build a mastercurve using $230^{\circ} \mathrm{C}$ as reference temperature (Figure 3 , right). The proximity to the glass transition was evidenced by the strong increase of G' and G" at high frequencies, while the upturn of ' $G$ ' at lower frequencies suggested the presence of entanglements or crosslinks. The dependency of the shift factors with temperature could not be fitted with the classical Williams-Landel-Ferry model (Figure $\mathrm{S} 12$ in $\mathrm{SI}$ ), but followed instead an Arrhenius model with a very high activation energy, about $500 \mathrm{~kJ} / \mathrm{mol}$. These uncommon features suggest that the mechanical relaxations associated to the glass transition are not governed by cooperative segmental motions, but rather by chemical exchanges. ${ }^{28}$ This polymer behaves therefore as a dynamic network with a unique glass-to-liquid transition. As lower frequencies could not be probed because of degradations starting to occur above $260^{\circ} \mathrm{C}$, we rather chose to further study highly plasticized PSBPin as a $50 \mathrm{wt} \%$ solution in xylenes $\left(\mathrm{bp} \approx 140^{\circ} \mathrm{C}\right)$. Monitoring in-situ the viscoelastic properties of this solution by small amplitude oscillations at $100^{\circ} \mathrm{C}$ (Figure 3, right) indicated initially a low-viscosity, followed by a strong increase in viscosity 
after about $10 \mathrm{~h}$. Upon shearing with large deformations, the viscosity suddenly dropped but grew again within $4 \mathrm{~h}$, showing this time a clear gelation with G'/G" crossover and an elastic modulus increasing up to $50 \mathrm{kPa}$. The slow and reversible buildup of elasticity here rather indicates a reversible crosslinking phenomenon than entanglement.
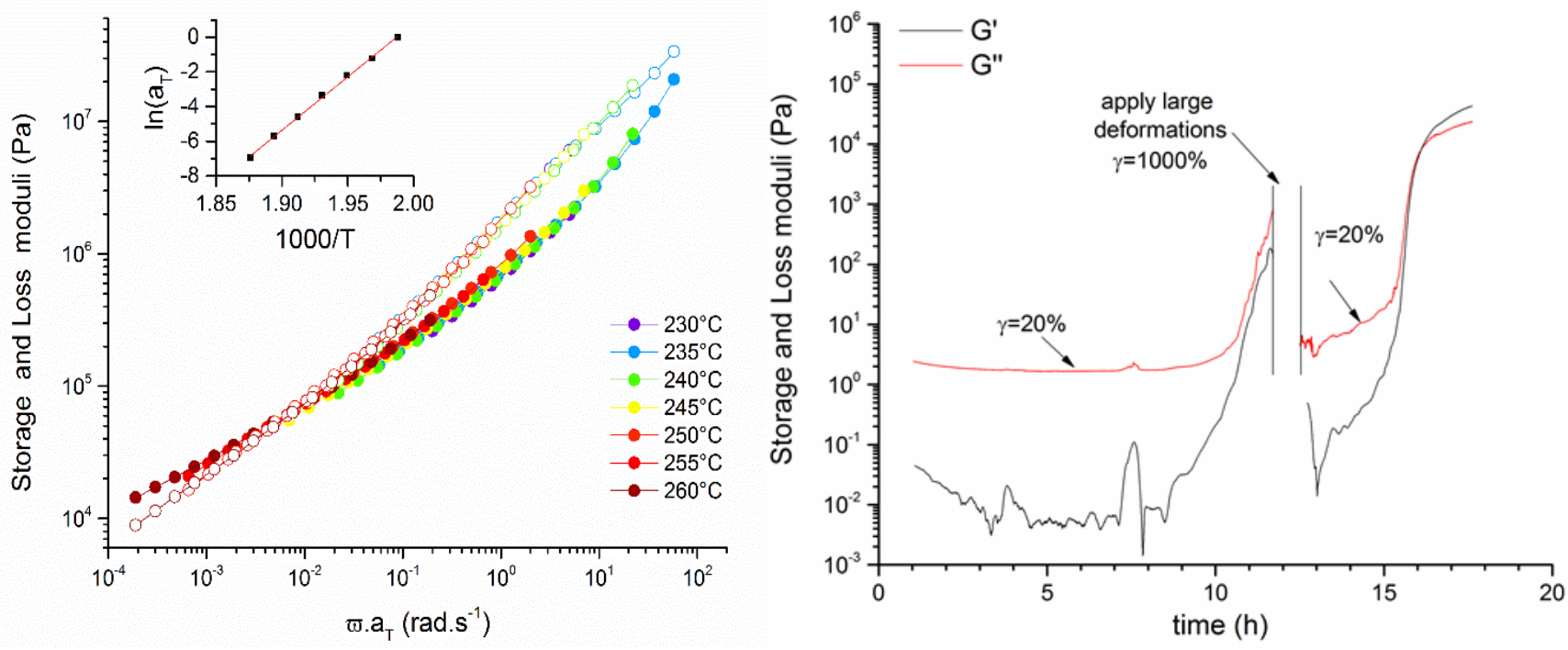

Figure 3. Left: Master curve of dynamic storage and loss moduli of PSBPin in bulk, referenced at $230^{\circ} \mathrm{C}$. Inset: Arrhenius-like dependency of the shift factors. Right: time monitoring of storage and loss moduli of PSBPin at $50 \mathrm{wt} \%$ in xylenes

The combination of DSC and rheology experiments thus indicates a dynamic crosslinking of PSBPin occurring very slowly in plasticized PSBPin at $100^{\circ} \mathrm{C}$. The presence of an endothermic reaction in bulk $\mathrm{PSBP}$ in in the $130-180^{\circ} \mathrm{C}$ range points towards an analogous, faster crosslinking. Despite our efforts, complete characterization of the dynamic-crosslinking density in bulk is not possible as the transition associated to chemical exchanges appears coincident with the segmental glass transition.

While we have established that PSBPin undergoes apparent crosslinking upon heating up to $200^{\circ} \mathrm{C}$ at $20 \mathrm{~K} / \mathrm{min}$, and even as concentrated solution over $10 \mathrm{~h}$ at $100^{\circ} \mathrm{C}$, we observed that the polymer could be completely resolubilised in most organic solvents after these heating treatments. Figure S17 in SI displays the SEC traces in toluene of fresh PSBPin and PSBPin taken from the DSC pan after multiple heating cycles. As no significant change occurred, it appears that the crosslinking reaction is dynamic, and can be fully reversed upon dilution (see Fig. 18 in $\mathrm{SI}$, for two complete cycles).

To better understand the reaction involved in the dynamic crosslinking, we carried out temperature-dependent FTIR measurements under inert atmosphere from 25 to $250^{\circ} \mathrm{C}\left(10^{\circ} \mathrm{C}\right.$ increments per hour) using a diffuse reflectance cell. The fresh PSBPin powder was used directly rather than samples obtained by hot or cold pressing. A few noticeable variations appeared in the $100-170^{\circ} \mathrm{C}$ range in the spectra (Figures S20 \& S21 in SI). Among them, two main changes raised our attention: a shouldering around $1370 \mathrm{~cm}^{-1}$ and a band shift from ca. 1170 to $1160 \mathrm{~cm}^{-1}$. These vibration modes involve torsions/elongations of the $\mathrm{O}-\mathrm{B}-\mathrm{O}$ as well as $\mathrm{C}-\mathrm{O}$ bonds of the pinacol motif as assigned by frequency calculations performed at the DFT level (M06/def2TZVP) on model pinacol phenyl boronate (see SI). This drove us to hypothesize a ring opening of the boronate cycles.
Solid-state boron NMR spectroscopy was therefore used to detect differences in the environment of the boron atoms of PSBPin before and after heating. ${ }^{11} \mathrm{~B}$ ss-NMR is not straightforward because of the quadrupolar nature of the ${ }^{11} \mathrm{~B}$ nucleus (spin $3 / 2$ ). Thus, when comparing signals, one should not conclude immediately from the maximum of intensity of the observable massif, but instead derive the isotropic chemical shift $\left(\delta \mathrm{i}_{\mathrm{so}}\right)$, the $\eta \mathrm{Q}$ values (related to the mobility of the corresponding boron atom) and observe the relative asymmetries/anisotropies of the signals. In our case, when superimposed, the two signal envelopes were distinct, suggesting an altered boron environment once PSBPin was exposed to high temperatures (Figure 4). To evaluate whether only one or several types of boron chemical environments were present, we used simulations from the "dmfit" program, which was specifically developed to account for quadrupolar couplings. ${ }^{29}$ One type of boron was sufficient to perfectly fit the experimental signal before heating. Conversely, two types of boron were necessary to achieve perfect match between simulation and experimental spectrum when fitting the signal after heating. Furthermore, the simulations established that the new type of boron formed after heating $(\sim 16 \mathrm{~mol} \%)$ had more symmetrical features, in particular quadrupolar couplings with lower $\eta \mathrm{Q}$ value (see Figure 4), and a different $\delta_{\text {iso }}$ of $32.5 \mathrm{ppm}$. This is indicative of an enhanced mobility and is compatible with boronate esters with pendant or intermolecular bridging pinacolates. The main environment was common to the samples before and after heating, with a $\delta \mathrm{i}_{\text {so }}$ of $30.5 \mathrm{ppm}$ before ( 30 after) and similar relatively high $\eta Q$ values $(0.71$ and 0.63 , respectively) thus indicative of a constrained geometry. It was attributed to native pinacol phenyl boronate cyclic species. The slight differences in $\delta_{\text {iso }}$ might come from residual solvent evaporation (toluene traces or adsorbed moisture no longer present after heating for $4 \mathrm{~h}$ at $200^{\circ} \mathrm{C}$ ). The newly formed type of boron displays an enhanced mobility, as can be expected when the ring opens. Therefore, ${ }^{11} \mathrm{~B}$ ss-NMR corroborates our hypothesis of ring 
opening of cyclic pinacol boronates. Interestingly, no sign of boroxine moieties could be evidenced, as these typically display a characteristic $\delta_{\text {iso }}$ around $60 \mathrm{ppm} .[30]$
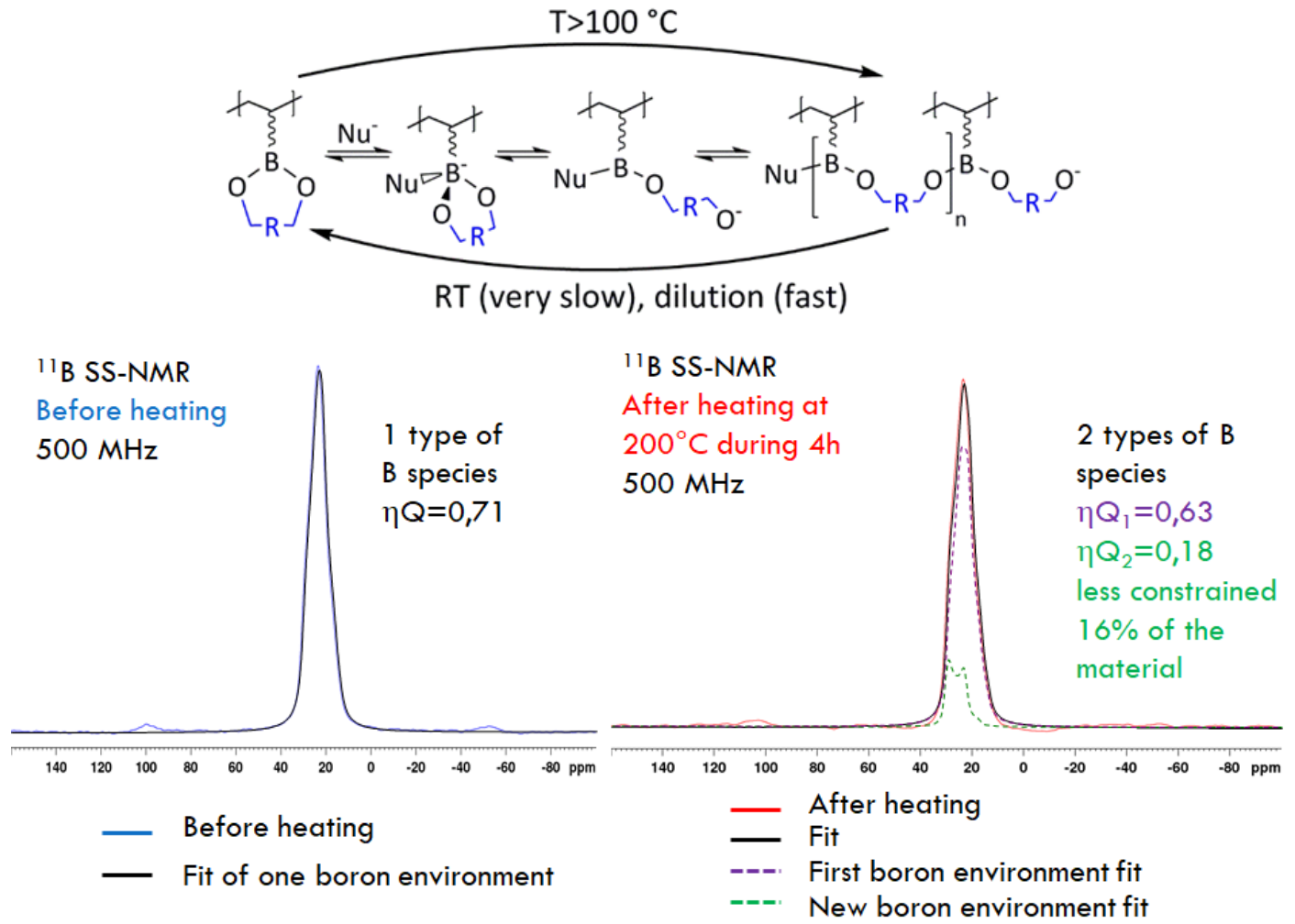

Figure 4. Solid-state ${ }^{11} \mathrm{~B}$ NMR study of poly(4-vinylphenylboronic acid, pinacol ester) (PSBPin). (Up) Putative mechanism, (Down, left) ${ }^{11} \mathrm{~B}$ NMR spectrum of native PSBPin and corresponding fit, (Down, right) ${ }^{11} \mathrm{~B}$ NMR spectrum of PSBPin after heating at $200^{\circ} \mathrm{C}$ for 4 hours and corresponding fits.

Taking into account the body of evidence obtained so far, we suggest that the ring opening of the boronates releases a free pinacolate moiety that can further reach neighbouring boron atoms thus acting as a rigid crosslink between PSBPin chains. This leads to a strong decrease in the chain mobility, consistently with the very high $\mathrm{T}_{\mathrm{g}}$ observed. DSC and rheology data corroborate this ring opening occurring at high temperatures (130$180^{\circ} \mathrm{C}$ ) and the dynamic character of the crosslinks formed.

Regarding the ring-opening initiation, involvement of a nucleophile and assistance by an acid seem compulsory: adventitious water or residual pinacol molecules remaining from the synthesis could fill both roles. The nucleophilic attack at boron and the subsequent ring opening would lead to singly-attached pinacol group readily available to initiate ring opening of a proximal pinacol boronate, ultimately triggering bridge formation. We resorted to computational mechanistic investigation performed at the DFT level in order to assess the enthalpy of ring opening of these pinacol boronates (details in $\mathrm{SI}$ ). In this investigation, PSBPin units have been represented by phenyl pinacol boronate and a water molecule has been used as prototype nucleophile. At room temperature, the interaction of $\mathrm{H}_{2} \mathrm{O}$ with a pinacol oxygen atom via $\mathrm{H}$-bonding is exothermic by $4.4 \mathrm{kcal}^{\mathrm{mol}}{ }^{-1}$ at $293 \mathrm{~K}$. This adduct will be taken as the energy reference hereafter. From this adduct, the subsequent ring opening to yield a singly-attached pinacol substituted boronic acid is endothermic by $3 \mathrm{kcal}^{\mathrm{mol}}{ }^{-1}$ (Figure S19, SI). In Gibbs energy, the reaction is endergonic by $4.0 \mathrm{kcal} . \mathrm{mol}^{-1}$. Consequently, the ring opening is slightly thermodynamically disfavoured but requires heating to circumvent the slight endothermicity/ endergonicity of the reaction. Indeed, the equilibrium between closed and open boronates will be slightly shifted towards the open form upon heating. This thermodynamic trend is consistent both with the net endothermic reaction measured by DSC (Figures S7 through S11, SI) and with crosslinking observed above $100^{\circ} \mathrm{C}$. We infer that this system, with a peculiar thermodynamic balance between the enthalpic and entropic contributions, is reminiscent of floor-temperature polymerizations already demonstrated in several low-strained cyclic monomers. ${ }^{31,32}$ Kinetically, the enthalpy (resp. Gibbs energy) barriers corresponding to ring opening is calculated at 27 (resp. 30) $\mathrm{kcal}^{\mathrm{mol}}{ }^{-1}$ above the water adduct, with a clear pyramidalisation induced by $\mathrm{H}_{2} \mathrm{O}$ nucleophilic attack at $\mathrm{B}$ through $\mathrm{O}$. Interestingly, the energy barrier corresponding to a direct metathesis has been estimated to $70 \mathrm{kcal} . \mathrm{mol}^{-1}$ relative to free pinacolboronate. This mechanism can thus be confidently ruled out.

Even though the overall entropy of the system would likely limit the extent of oligomerisation, bridging between boron atoms appears sufficient to trigger dense crosslinking in these highly functional polymers at high temperature. Furthermore, the decrosslinking induced at high dilutions is likely entropically driven by the formation of the more favoured intramolecular 5-membered 
cycle in the presence of a high concentration of solvent molecules. This de-crosslinking should also be favoured at low temperatures but is most probably kinetically frozen by the glass transition in PSBPin.

In order to verify this mechanism, we performed double-tagging experiments. If the dynamic character of the ring-opening oligomerization is effectively due to the living character of the pendant pinacolate groups, we should not only observe oligomerisation and depolymerisation of the model molecules, but also backbiting or chain shuffling that could result in more complex rearrangements and effective exchange of substituents between boronate esters (Figure 5). These exchanges should be evidenced by double tagging: we therefore prepared two phenylboronate esters $\mathrm{A}$ and $\mathrm{B}$ (Figure 5 , section 5 of $\mathrm{SI}$ ). A has a phenyl ring and its diol component is 1,2-ethanediol while $B$ has a fluorine tag on the phenyl part and pinacol as its diol. The fluorine substituent enables straightforward quantification of any diol exchanged by ${ }^{19} \mathrm{~F}$ NMR, while only marginally affecting the intrinsic reactivity at the boron atom. The boronates $A$ and $B$ were mixed without additional solvent in a NMR tube and heated at $100^{\circ} \mathrm{C}$. Periodically, the NMR tube was cooled at room temperature, equipped with an insert filled with Toluene-d8 to lock the NMR apparatus and analysed with ${ }^{19} \mathrm{~F}$ NMR. While only A could initially be observed, a new species appeared with time that was attributed to the F-tagged phenyl boronate bearing an ethylene glycol group (C, Figure 5). The attribution of the new ${ }^{19} \mathrm{~F}$ NMR signal to $C$ was confirmed by separately synthesising the 4fluoro-phenyl boronate of ethylene glycol (Figures S22 \& S23, SI). Integration of the signals corresponding to $A$ and $C$ at $-107.8 \mathrm{ppm}$ and $-108.2 \mathrm{ppm}$, respectively, showed that a nearly $1: 1$ equilibrium was reached after $50 \mathrm{~h}$.

In order to support our hypothesis that the crosslinks were initiated by the adventitious nucleophiles still present in the sample, we added $50 \mathrm{~mol} \%$ of benzyl alcohol - a non-volatile nucleophile - in the initial mixture. ${ }^{19} \mathrm{~F}$ NMR monitoring at $100^{\circ} \mathrm{C}$ showed a much faster exchange rate, as the $A$ / C 1:1 equilibrium was reached within $12 \mathrm{~h}$. In addition, smaller new signals could be observed on the ${ }^{19} \mathrm{~F}$ NMR spectra, which we believe are those of the benzyl-alcohol derived phenyl boronates and several other products/intermediates of the exchange reaction (e.g. the tetragonal intermediates), which was partially confirmed by ${ }^{19} \mathrm{~F}$ DOSY NMR experiments (section 5 of SI, Figures S22 to S27). If these results are consistent with previously reported doubletagging experiments [22] using GC as an analytical method of choice, they are based on a very-straightforward NMR complementary strategy, and clearly evidence the advantageous nucleophilic assistance authorizing the exchange derived from boronate-ester ring opening.

In light of these experiments, adventitious nucleophiles present in bulk PSBPin are thus expected to accelerate the dynamics of equilibration between cyclic pinacol boronates and bridging pinacol units. Additional DSC experiments on fresh PSBPin sample ran in high-pressure sealed pans enabled to suppress evaporation endotherms (Figures S7 \& S9, SI). In such conditions, we also observed a unique endotherm between 90 and $110^{\circ} \mathrm{C}$, but the $\mathrm{Tg}$ is dramatically lowered to $160^{\circ} \mathrm{C}$, even after multiple heating cycles. We believe that water adsorbed and minute amounts of pinacol remaining in the PSBPin sample are responsible for faster dynamics and thus a lower $\mathrm{Tg}$ of the material, possibly also acting to a lesser extent as a plasticizer.

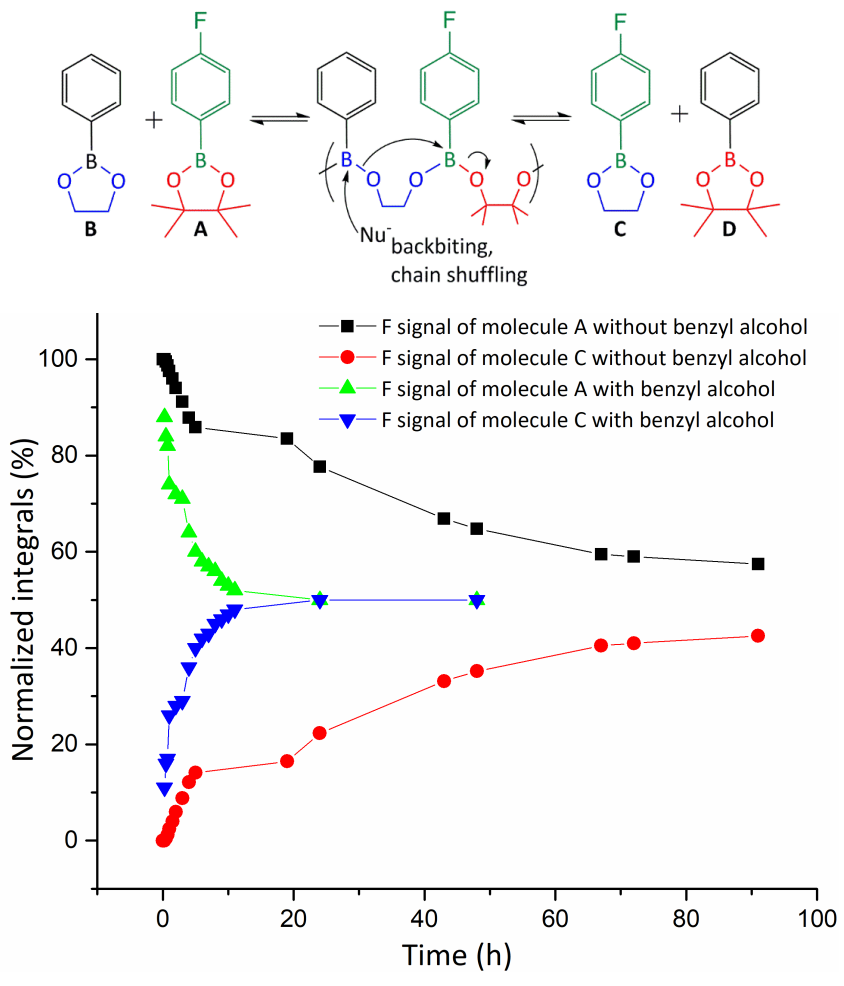

Figure 5. Double-tagging experiments using ${ }^{19} \mathrm{~F}$ NMR spectroscopy.

Dynamic gelation of a 50 wt \% concentrated PSBPin solution in toluene in presence of $2 \mathrm{~mol} \%$ of benzyl alcohol is illustrated in Figure 6 (Figure S18, SI). After heating the viscous solution for 72 $\mathrm{h}$ at $100^{\circ} \mathrm{C}$, gelation was observed. Upon cooling to room temperature and further addition of toluene (the final concentration is 25 wt \% PSBPin), immediate swelling was visible. After $2 \mathrm{~min}$, the gel was fully broken and a low-viscosity solution was obtained. Two full cycles were performed on the material to evidence the dynamic character of the crosslinking and its complete reversibility (see SI, Fig. S18).

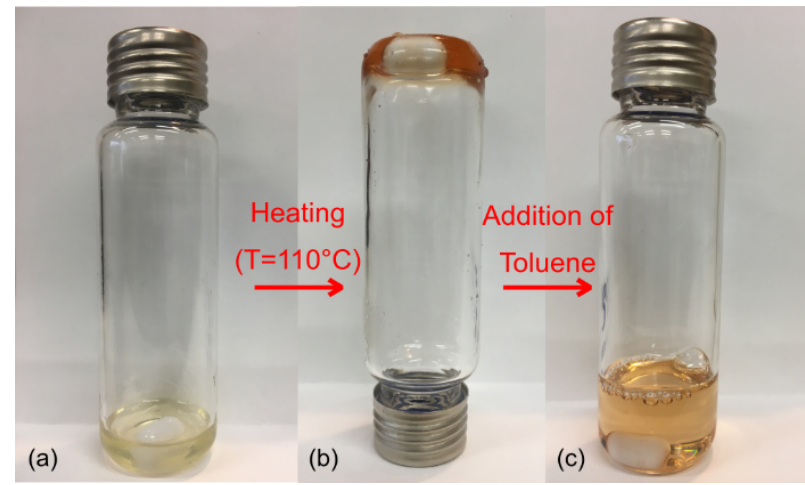

Figure 1. Macroscopic observations of the reversible crosslinking of an originally $50 \mathrm{wt} \%$ concentrated PSBPin solution in toluene. (a) Initial solution of poly(4-vinylphenylboronic pinacolate) at 50 wt $\%$ in toluene with $2 \%$ molar equivalent of benzyl alcohol, (b) After 1 night at $110^{\circ} \mathrm{C}$, (c) $t=2$ min after the addition of $2 \mathrm{~mL}$ of toluene.

\section{Conclusion}


We have demonstrated through a variety of thermomechanical and spectroscopic techniques (DSC, rheology, FTIR, ${ }^{11} \mathrm{~B}$ ssNMR) that above $100^{\circ} \mathrm{C}$ boronate-ester ring opening occurs in poly(4-vinylphenylboronic pinacolate)s and related copolymers, leading to interchain bridging between boron moieties and high$\mathrm{T}_{\mathrm{g}}$ (up to $220^{\circ} \mathrm{C}$ ) polymer networks. Direct exchange of 1,2-diol substituents was evidenced on model compounds by ${ }^{19} \mathrm{~F}$ NMR spectroscopy, and confirms the dynamic character of the ring opening and the importance of nucleophilic assistance to trigger it. This phenomenon appears to be reversible by dilution in apolar solvents. The peculiar thermodynamics of this ring opening/closing sequence, supported by DFT calculations, favour depolymerisation at room temperature and oligomerisation at high temperatures. The very fact that bridging between boron atoms lead to high glass transition temperatures in our system and subsequently froze the depolymerisation kinetics was critical in evidencing these dynamic crosslinking phenomena. When comparing our system to vitrimers and CANs, that have either constant crosslinking densities or decreasing crosslinking densities with temperature, it is exciting to note that polymers bearing cyclic boronate esters may constitute the first example of a distinct class of dynamic networks, with a crosslinking density increasing with temperature, at least within a defined temperature range.

\section{Experimental Section}

Unless otherwise stated, all reactions were conducted under inert atmosphere (argon) using standard techniques for manipulating airsensitive compounds. All glassware was stored in an oven or was flamedried prior to establishing an argon atmosphere. Yields refer to spectroscopically pure compounds. The reagents were purchased from Combi Blocks and Sigma Aldrich and used without any further purification. The polymerization solvents were purified by freeze-pump-thaw technique. 4-vinylphenylboronic acid $(10,0 \mathrm{~g}, 67.6 \mathrm{mmol})$ and pinacol $(8.03 \mathrm{~g}, 68.0$ $\mathrm{mmol})$ as well as $0.05 \mathrm{~mL}$ distilled water were stirred in THF $(100 \mathrm{~mL})$ at room temperature for $30 \mathrm{~min}$. Then $2 \mathrm{~g}$ of anhydrous magnesium sulfate were added to the solution and stirred at room temperature for $2 \mathrm{~h}$. The mixture was filtered and volatiles were removed under vacuum to yield a clear yellow oil. Yield: $14.7 \mathrm{~g}, 95 \% .4$-vinylphenylboronic acid, pinacol ester $(3.8 \mathrm{~g}, 16 \mathrm{mmol})$ and benzoyl peroxide $(0.02 \mathrm{eq}, 0.33 \mathrm{mmol}, 80 \mathrm{mg})$ were introduced in a Schlenk vessel with $3.8 \mathrm{~mL}$ toluene (degassed by three freeze-pump-thawing cycles). The polymerization was conducted at $70^{\circ} \mathrm{C}$ during $72 \mathrm{~h}$. Then, the reaction media was precipitated in pentane and the solid was obtained by filtration and dried under vacuum for one night. The polymer was obtained as a white powder. Yield: $87 \%$. In order to minimize any residual functionality in the final polymer, we used benzoyl peroxide (BPO) as a nitrogen-free initiator (Figure 1; see sections 2, 3 and 4 of Supporting Information for further details \& characterization).

\section{Acknowledgements ((optional))}

J.B. thanks the University of Claude Bernard Lyon 1 for funding L. P. thanks the CCIR of ICBMS and P2CHP of Université Lyon 1 for providing computational resources and technical support. The authors thank A. Baudouin and D. Gajan respectively for liquidand solid-state NMR spectroscopy, K. Szeto for DRIFT experiments, and the SEC characterization platform of the LPSE.

Keywords: boron chemistry $\cdot$ organoboron polymers $\bullet$ high glass-transition temperature $\cdot$ dynamic networks $\cdot$ reversible crosslinking
[1] ((Reference 1, Example for Journals:)) a) A. Author, B. Coauthor, ChemSusChem 2008, 1, 1-10; b) A. Author, B. Coauthor, Angew. Chem. 2006, 118, 1-5; Angew. Chem. Int. Ed. 2006, 45, 1-5.

[2] ((Reference 2: Example for Books:)) J. W. Grate, G. C. Frye in Sensors Update, Vol. 2 (Eds.: H. Baltes, W. Göpel, J. Hesse), Wiley-VCH, Weinheim, 1996, pp. 10-20.

Jäkle, F. Chemical Reviews 2010, 110, 3985-4022

2 Brooks, W. L. A. \& Sumerlin, B. S. Chemical Reviews 2016, 116, 13751397

3 Molander, G. A. \& Ellis, N. Accounts of Chemical Research 2007, 40, 275-286.

4 Gillis, E. P. \& Burke, M. D. Journal of the American Chemical Society 2008, 130, 14084-14085.

$5 \quad$ Knapp, D. M., Gillis, E. P. \& Burke, M. D. A General Solution for Unstable Boronic Acids: Slow-Release Cross-Coupling from Air-Stable MIDA Boronates. Journal of the American Chemical Society 131, 6961-6963, doi:10.1021/ja901416p (2009).

6 Partyka, D. V. Transmetalation of Unsaturated Carbon Nucleophiles from Boron-Containing Species to the Mid to Late d-Block Metals of Relevance to Catalytic C-X Coupling Reactions $(X=C, F, N, O, P b, S$, Se, Te). Chemical Reviews 111, 1529-1595, doi:10.1021/cr1002276 (2011).

7 Biffis, A., Centomo, P., Del Zotto, A. \& Zecca, M. Pd Metal Catalysts for Cross-Couplings and Related Reactions in the 21st Century: A Critical Review. Chemical Reviews 118, 2249-2295, doi:10.1021/acs.chemrev.7b00443 (2018)

8 Cambre, J. N. \& Sumerlin, B. S. Biomedical applications of boronic acid polymers. Polymer 52, 4631-4643, doi: 10.1016/j.polymer.2011.07.057 (2011).

9 Yang, W., Gao, X. \& Wang, B. Biological and Medicinal Applications of Boronic Acids. Boronic Acids, doi:10.1002/3527606548.ch13 (2006).

10 Kataoka, K., Miyazaki, H., Bunya, M., Okano, T. \& Sakurai, Y. Totally Synthetic Polymer Gels Responding to External Glucose Concentration: Their Preparation and Application to On-Off Regulation of Insulin Release. Journal of the American Chemical Society 120, 12694-12695, doi:10.1021/ja982975d (1998).

11 Cromwell, O. R., Chung, J. \& Guan, Z. Malleable and Self-Healing Covalent Polymer Networks through Tunable Dynamic Boronic Ester Bonds. J Am Chem Soc 137, 6492-6495, doi:10.1021/jacs.5b03551 (2015).

12 Cash, J. J., Kubo, T., Bapat, A. P. \& Sumerlin, B. S. Room-Temperature Self-Healing Polymers Based on Dynamic-Covalent Boronic Esters. Macromolecules 48, 2098-2106, doi:10.1021/acs.macromol.5b00210 (2015)

13 Montarnal D. Capelot M., Tournilhac, F. \& Leibler, L Silica-Like Malleable Materials from Permanent Organic Networks. Science 334 965, doi:10.1126/science.1212648 (2011).

14 Denissen, W., Winne, J. M. \& Du Prez, F. E. Vitrimers: permanent organic networks with glass-like fluidity. Chemical Science 7, 30-38, doi:10.1039/C5SC02223A (2016).

15 Imbernon, L. \& Norvez, S. From landfilling to vitrimer chemistry in rubber life cycle. European Polymer Journal 82, 347-376, doi: 10.1016/j.eurpolymi.2016.03.016 (2016).

16 Worrell, B. T. et al. Bistable and photoswitchable states of matter. Nature Communications 9, 2804, doi:10.1038/s41467-018-05300-7 (2018).

17 Chen, X. et al. A Thermally Re-mendable Cross-Linked Polymeric Material. Science 295, 1698, doi:10.1126/science.1065879 (2002).

18 Bowman, C. N. \& Kloxin, C. J. Covalent Adaptable Networks: Reversible Bond Structures Incorporated in Polymer Networks. Angewandte Chemie International Edition 51, 4272-4274, doi:10.1002/anie.201200708 (2012).

19 Wojtecki, R. J., Meador, M. A. \& Rowan, S. J. Using the dynamic bond to access macroscopically responsive structurally dynamic polymers. Nature Materials 10, 14-27, doi:10.1038/nmat2891 (2011).

20 Zou, W., Dong, J., Luo, Y., Zhao, Q. \& Xie, T. Dynamic Covalent Polymer Networks: from Old Chemistry to Modern Day Innovations. Advanced Materials 29, doi:10.1002/adma.201606100 (2017)

21 Cromwell, O. R., Chung, J. \& Guan, Z. Malleable and Self-Healing Covalent Polymer Networks through Tunable Dynamic Boronic Ester Bonds. Journal of the American Chemical Society 137, 6492-6495, doi:10.1021/jacs.5b03551 (2015).

22 Rottger, $\mathrm{M}$. et al. High-performance vitrimers from commodity thermoplastics through dioxaborolane metathesis. Science 356, 62-65, doi:10.1126/science.aah5281 (2017).

23 Kyriacos, D. Chapter 21 - High-Temperature Engineering Thermoplastics in Brydson's Plastics Materials (Eighth Edition), 545-615, doi:10.1016/B978-0-323-35824-8.00021-9 (2017). 
24 Kaiser, T. Highly crosslinked polymers. Progress in Polymer Science 14 373-450, doi: 10.1016/0079-6700(89)90007-5 (1989).

25 Liu, T. et al. A Self-Healable High Glass Transition Temperature Bioepoxy Material Based on Vitrimer Chemistry. Macromolecules 51 5577-5585, doi:10.1021/acs.macromol.8b01010 (2018).

26 Qin, Y. Sukul, V., Pagakos, D., Cui, C \& Jäkle, F. Preparation of Organoboron Block Copolymers via ATRP of Silicon and BoronFunctionalized Monomers. Macromolecules 38, 8987-8990, doi:10.1021/ma051615p (2005)

27 Letsinger, R. L. \& Hamilton, S. B. Organoboron Compounds. X.1,2 Popcorn Polymers and Highly Cross-linked Vinyl Polymers Containing Boron. Journal of the American Chemical Society 81, 3009-3012, doi:10.1021/ja01521a023 (1959).

28 Capelot, M., Unterlass, M. M., Tournilhac, F. \& Leibler, L. Catalytic Control of the Vitrimer Glass Transition. ACS Macro Letters 1, 789-792, doi:10.1021/mz300239f (2012).

29 Massiot, D. et al. Modelling one- and two-dimensional solid-state NMR spectra. 40, 70-76, doi: 10.1002/mrc.984 (2002).

30 Penczek, S. et al. Thermodynamics and kinetics of ring-opening polymerization of cyclic alkylene phosphates. 73, 91-101, doi: 10.1002/masy.19930730110 (1993).

30 Penczek, S. et al. Thermodynamics and kinetics of ring-opening polymerization of cyclic alkylene phosphates. 73, 91-101, doi: 10.1002/masy.19930730110 (1993).

31 Strandman, S., Gautrot, J. E. \& Zhu, X. X. Recent advances in entropydriven ring-opening polymerizations. Polymer Chemistry 2, 791-799, doi:10.1039/COPY00328J (2011) 
Entry for the Table of Contents (Please choose one layout)

Layout 1:

\section{RESEARCH ARTICLE}

Styrenic-based polymers bearing pendent pinacol-boronate ester groups are able to crosslink into dense networks with glass transition temperature as high as $220^{\circ} \mathrm{C}$. This crosslinking is based on an overlooked dynamic ring opening of cyclic boronates promoting bridging between boron atoms, and is fully reversible upon dilution at ambient temperatures.

Layout 2:

\section{RESEARCH ARTICLE}

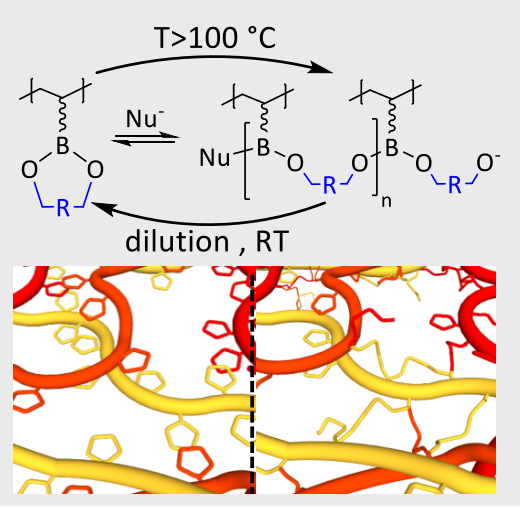

Juliette Brunet, Franck Collas, Matthieu Humbert, Lionel Perrin, Fabrice Brunel, Emmanuel Lacôte, Damien Montarnal*, Jean Raynaud*

Page No. - Page No.

High glass-transition temperature polymer networks harnessing the dynamic ring opening of pinacol boronates
Author(s), Corresponding Author(s)*

Page No. - Page No.

Title 